\title{
Retraction Note to: Magnetic resonance imaging evaluation of intervertebral test spacers: an experimental comparison of magnesium versus titanium and carbon fiber reinforced polymers as biomaterials
}

\author{
T. Ernstberger · G. Buchhorn · G. Heidrich
}

Published online: 13 February 2015

(C) Royal Academy of Medicine in Ireland 2015

Retraction to: Ir J Med Sci (2010) 179:107-111

DOI 10.1007/s11845-009-0394-5

The above named article is to be retracted from the Irish Journal of Medical Science. As a result of poor communication, the manuscript was submitted to Neuroradiology whilst still under consideration by the Irish Journal of Medical Science, and subsequently published online by Neuroradiology on 26th May 2009. The article was published online within the Irish Journal of Medical Science on 20th August 2009; due to being the latter of the two article versions, we have decided to retract the article.

Readers wishing to access the article content can do so at Neuroradiology, August 2009, Volume 51, Issue 8, pp 525-529, doi:10.1007/s00234-009-0537-4.

James F.X. Jones

Editor-in-Chief, Irish Journal of Medical Science

The online version of the original article can be found under doi:10.1007/s11845-009-0394-5.

T. Ernstberger $(\bowtie)$

Department of Orthopaedic Surgery, University of Göttingen,

Robert-Koch-Straße 40, 37075 Göttingen, Germany

e-mail: ternstberger@med.uni-goettingen.de

G. Buchhorn

Biomaterial Laboratory, Department of Orthopaedic Surgery,

University of Göttingen, Göttingen, Germany

G. Heidrich

Department of Diagnostic Radiology, University of Göttingen,

Göttingen, Germany 